\title{
Post-stroke dementia: frequency, predictors, and health impact
}

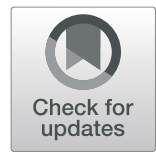

\author{
Bastawy Al Fawal', Ahmed Ibrahim ${ }^{2}$ and Mohamed Abd Elhamed ${ }^{3^{*}}$ (D)
}

\begin{abstract}
Background: Cognitive impairment is an important aspect for stroke survivors. Little data are available about the frequency and risk factors of post-stroke dementia in Egypt.

Objectives: The aim of this study is to evaluate the frequency and predictors of post-stroke dementia and its impact on outcome.

Methods: A total of 380 patients with acute stroke were included. Patients were subjected to demographic data collection, neurological examination, and assessment of vascular risk factors. Furthermore, assessment of stroke severity by Barthel Index was done. After 6 months, patients were assessed for outcome and development of poststroke dementia.

Results: Post-stroke dementia was detected in $20.8 \%$ of patient. It was recorded more in old ages, illiterates, unmarried, unemployed, and those with recurrent stroke and with cerebral infarction (significantly with cardioembolic).

Conclusion: Post-stroke dementia is high in Egypt, especially in those with illiteracy, atrial fibrillation, brain atrophy, severe strokes, and those presented with hemiplegia, sphincter affection, abnormal gait, and psychotic features. Assessment for post-stroke dementia should be done during follow up of stroke patients.
\end{abstract}

Keywords: Post-stroke dementia, Barthel Index, Cognitive impairment

\section{Introduction}

Cerebrovascular stroke (CVS) is one of the leading causes of mortality and disability worldwide [1]. Many patients are left with residual cognitive deficits [2, 3]. Post-stroke dementia (PSD) is the second most common cause of dementia [4] and one of the main causes of dependency in survivors [5]. About one-third of stroke survivors are found to have a significant degree of cognitive impairment within the first months after the event [6].

The prevalence of PSD in stroke survivors is about $30 \%$ and having a stroke doubles the risk of dementia [7]. The risk factors for PSD are multifactorial and

\footnotetext{
*Correspondence: moh78_abdelhamed@aun.edu.eg; moh78_abdelhamed@yahoo.com

${ }^{3}$ Neurology and Psychiatry Department, and Neuroepidemiology Laboratory, Faculty of Medicine, Assiut University, Assiut University street,

Neuropsychiatric Hospital, 7th floor, Assiut 71926, Egypt

Full list of author information is available at the end of the article
}

include genetic predisposition, demographic factors such as old age and low education, pre-stroke cognitive and functional status, number of prior transient ischemic attacks or strokes, and vascular risk factors of stroke [8].

The mechanism of PSD remains unclear and its pathological substrates are poorly understood, but the most accepted theory is that the heterogeneous nature of vascular lesions of stroke may have an effect on cognition through altered blood and oxygen supply to brain tissues, chronic inflammation, disruption of axonal tracts, or altered cortical connectivity [9]. Moreover, medical comorbidities such as hypertension and diabetes mellitus can cause cerebral hypoxia or ischemia leading to cerebral hypoperfusion, which serves as a basis for PSD [7].

In a study in NY, USA, dementia diagnosed 3 months after stroke was associated with triple increase in the risk of stroke recurrence and might be a surrogate marker for more severe vascular disease leading to lack of 
compliance that can contribute to worse outcome [10]. Several studies have shown that PSD was independently associated with increased post-stroke mortality, after adjusting for vascular risk factors and stroke severity [11, 12].

To the best of our knowledge, data about the frequency and risk factors of PSD is still deficient in Egypt and we hypothesize that the frequency and risk factors of PSD varied among different populations due to different genetic and environmental factors. So, this article aimed to discuss the frequency, risk factors, and impacts of PSD on outcome, and consequently recommended early and optimal intervention in the window before dementia sets in for proper health plan.

\section{Methods}

The current work was a prospective cohort study. Three hundred eighty patients with acute cerebrovascular stroke (within 1 week) were recruited from stroke unit and neurology ward, and followed up at outpatient clinics of Assiut and Aswan University Hospitals from September 2017 to August 2019 and included in this study.

Patients with transient ischemic attack, brain lesions other than stroke such as brain tumors, with unreliable informant, refuse to participate, known to have serious renal, hepatic dysfunction. Patients with known psychiatric disease, or have mild cognitive impairment and other types of dementia from the history (diagnosed according to DSM-V), inability to communicate such as sensory aphasia and those receiving medications that affect cognition such as antipsychotics and antidepressants were excluded from the study.

To confirm the diagnosis of stroke, all patients underwent CT and /or MRI brain. Patients were classified according to their clinical picture and neuroimaging into ischemic and haemorrhagic stroke (cerebral and subarachnoid hemorrhage) with localization of cerebral lesions.

Data on self or family reported risk factors for stroke, including socio-demographics, hypertension, diabetes mellitus, heart diseases, smoking, family history, and number of recurrence of stroke, were obtained from the patient/or his caregivers. At time of admission, all patients were subjected to meticulous neurological and general examination. Assessment of lipid profile was performed to all patients, where hypercholesterolemia and hypertriglyceridemia were considered when serum levels $>239 \mathrm{mg} / \mathrm{dl}$ and $>200 \mathrm{mg} / \mathrm{dl}$ respectively [13]. Electrocardiography (ECG) and/or echocardiography were performed to determine any arrhythmias and/or any ischemia (CON-TEC, model: ECG100G, China).

Assessment of patients by Barthel Index (BI) [14] was done at the onset of stroke and 6 months later. The severity of all strokes was determined, where there were three grades; very poor: complete dependence (BI score $<60$ ), poor: assisted independence (BI score $60-<95$ ), and excellent: minimal or no disability (BI score $\geq 95$ ). Stroke was considered severe when the patient had poor or very poor grade on $\mathrm{BI}$.

Within 6 months from onset, all patients were evaluated for the development of PSD. The diagnosis of dementia was made according to Hachinski Ischemic Score [15] and the criteria of vascular dementia in the DSM-V [16]. Mini-Mental State Examination (MMSE) was performed to detect dementia and its grades, where patients with scores $19 \leq 23$ ( $17 \leq 21$ for illiterates) were diagnosed to have mild dementia, $10<19(9<17$ for illiterates) have moderate, and $<10(<9$ for illiterates) to have severe dementia [17]. The outcome of all CVS patients was assessed clinically and by BI by the end of the 6 months.

Sample size calculation was carried out using G*Power 3 software [18]. A calculated minimum sample of 154 stroke patients divided into two groups (77 with PSD and 77 without PSD) were needed to detect an effect size of 0.1 in the mean GCS, MMSE, and BI, with an error probability of 0.05 and $90 \%$ power on a two-tailed test. The sample was raised to include 79 with and 301 without PSD.

Data were processed by the researchers and analyzed using IBM-SPSS 21.0 (IBM-SPSS Inc., Chicago, IL, USA) [19]. Descriptive statistics: means, standard deviations, and percentages were calculated. Test of significances: chi-square test was used to compare the difference in distribution of frequencies among different groups. Independent $t$ test analysis was carried out to compare the means of dichotomous data. Significant variables from the univariate analysis were entered in multivariable logistic regression model to test the independent predictors of dementia in patients with stroke using odds ratio (OR), 95\% confidence interval (CI), and $p$ value. A significant $p$ value was considered when it is equal or less than 0.05 .

\section{Results}

A total number of 432 stroke patients were assessed for eligibility criteria. Twenty-two of them were excluded because they did not met the inclusion criteria, while thirty patients dropped out during the follow up (Fig. 1). Among the 380 stroke patients included and completed the current study, $20.8 \%$ developed dementia.

The mean PSD patients' age was $71.6 \pm 9.8$ years. PSD was detected in $19.8 \%$ and $22 \%$ of male and female patients, respectively. Also, it was detected in about onequarter $(24.3 \%)$ and one-fifth $(19.5 \%)$ of rural and urban inhabitant patients, respectively. Furthermore, PSD was recorded in about three-quarters (76\%) and four-fifth 


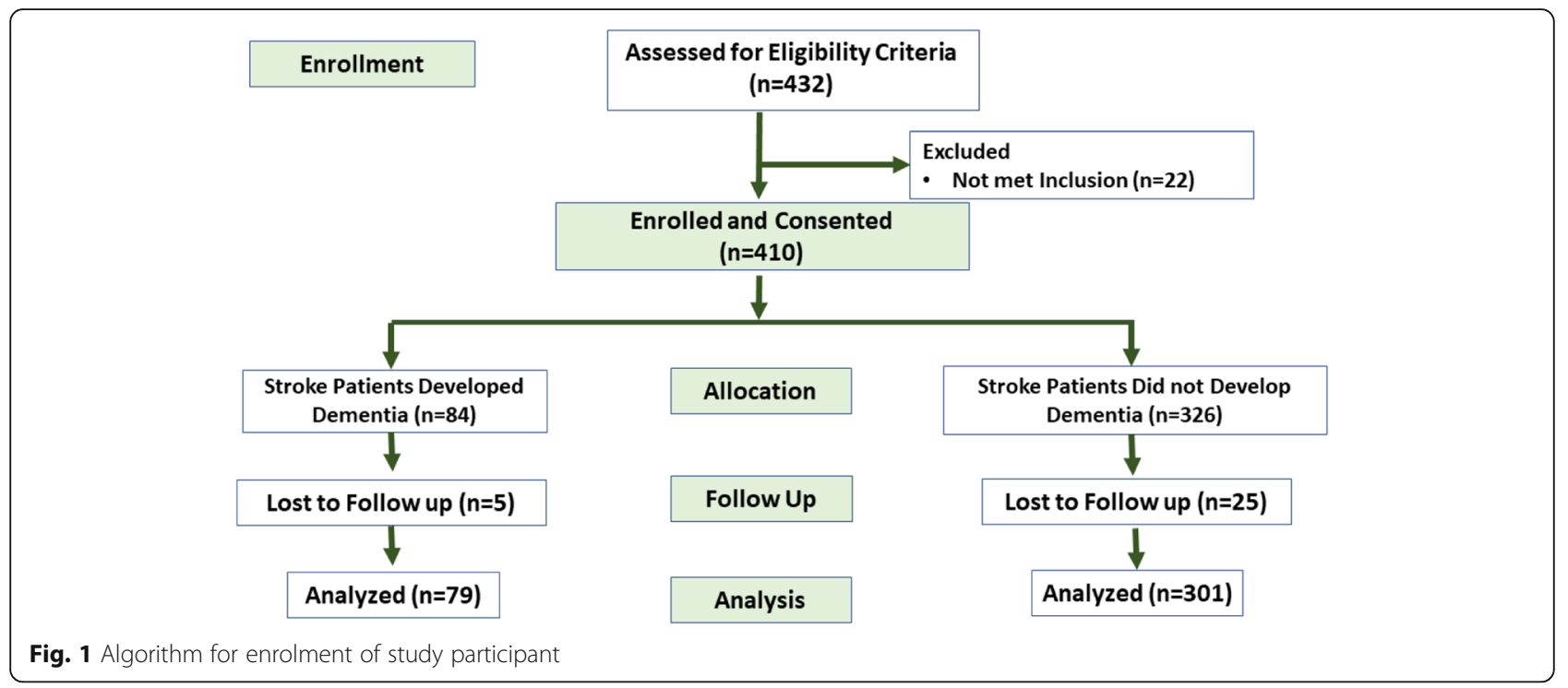

(81\%) of illiterate and non-working patients, respectively (Table 1).

Vascular risk factors such as hypertension, diabetes mellitus, and dyslipidaemias had statistically insignificant effect on PSD $(P>0.05)$. On the other hand, AF was reported among $21.5 \%$ of PSD versus $2.7 \%$ of patients without PSD with statistically significant difference $(P<$ 0.001). Moreover, PSD was recorded more in patients with recurrent stroke (Table 2).

Table 3 demonstrated that PSD developed significantly more in patients with severe initial stroke, and in those with certain clinical and neuroimaging presentations $(\leq$ 0.01 ). In addition, it developed more significantly in patients with cerebral infarction $(P=0.044)$, especially in those with cardio-embolic strokes $(P<0.001)$. Assessment of the degree of PSD according to MMSE scores revealed that $27.8 \%$ of cases of PSD were mild, $63.3 \%$ were moderate, and only $8.9 \%$ had severe dementia (Fig. 2).

After adjusting for age and sex, the final multivariate model contained eight independent predictors, illiteracy, AF, brain atrophy, poor prognosis, hemiplegia, sphincteric affection, abnormal gait, and psychotic features at onset. In other words, illiterate patients and those with AF were 1.6 and 6.1 times more at risk of having PSD [AOR $=1.60$ and 6.11, $P=0.041$ and 0.005 , respectively] (Table 4).

Figure 3 showed the patient's improvement. According to clinical evaluation, the majority of patients with PSD (98.7\%) either did not improve or deteriorated compared to $36.5 \%$ of those without dementia $(P<0.001)$. Likewise, about three-quarters $(77.2 \%)$ of patients with PSD had poor/very poor outcome as compared to less than half $(45.5 \%)$ of patients without dementia, according to BI $(P<0.001)$.

\section{Discussion}

Prevalence of PSD has been found to be higher than previously expected, its course is non-linear, being higher in the first 6 months after stroke, and it is reported to be between 6 and 32\%. This wide range may be due to methodological differences [20]. In our hospital-based study, the frequency of PSD was $20.8 \%$, which was comparable to previous studies; (19.3\%) in America, (23.2\%) in Iran, and (24.6\%) in Italy [21, 22].

Table 1 Sociodemographic characteristics of the studied stroke cases

\begin{tabular}{llll}
\hline Variable & Without PSD $(\boldsymbol{n = 3 0 1 )}$ & With PSD $(\boldsymbol{n}=\mathbf{7 9})$ & $\boldsymbol{P}$ value \\
\hline Age/years & $58.90 \pm 11.6$ & $71.63 \pm 9.8$ & $<\mathbf{0 . 0 0 1}^{*}$ \\
Sex (male/female) & $170 / 131$ & $42 / 37$ & $=0.344^{* *}$ \\
Residence (rural/urban) & $78 / 223$ & $25 / 54$ & $=0.234^{* *}$ \\
Work status (unemployed) & $189(62.8 \%)$ & $64(81 \%)$ & $\mathbf{0 . 0 0 2 ^ { * * }}$ \\
Illiterate & $132(43.9 \%)$ & $60(75.9 \%)$ & $<\mathbf{0 . 0 0 1}^{* *}$ \\
Marital status (unmarried) & $63(20.9 \%)$ & $31(39.2 \%)$ & $=\mathbf{0 . 0 0 1 ^ { * * }}$ \\
\hline
\end{tabular}

*Independent $t$ test was used to compare the means among groups

${ }^{*}$ Chi-square analysis was used to compare the frequency among groups

$P S D$ :post stroke dementia 
Table 2 Risk factors comparisons among the studied stroke cases

\begin{tabular}{llll}
\hline Variable & Without PSD $(\boldsymbol{n}=\mathbf{3 0 1})$ & With PSD $(\boldsymbol{n}=\mathbf{7 9})$ & P value \\
\hline \multicolumn{1}{c}{ Hypertension } & $170(56.5 \%)$ & $50(63.3 \%)$ & $=0.275^{*}$ \\
\multicolumn{1}{c|}{ DM } & $116(38.5 \%)$ & $34(43 \%)$ & $<.446^{*}$ \\
AF & $8(2.7 \%)$ & $17(21.5 \%)$ & $=0.001^{*}$ \\
Triglycerides $(\mathrm{mg} / \mathrm{dl})$ & $181.17 \pm 19.9$ & $182.19 \pm 16.7$ & $=0.941^{* *}$ \\
Cholesterol $(\mathrm{mg} / \mathrm{dl})$ & $210.80 \pm 52.4$ & $215.88 \pm 49.4$ & $=0.423^{* *}$ \\
Family history of stroke & $19(6.3 \%)$ & $7(8.9 \%)$ & $=0.282^{*}$ \\
Stroke recurrence & $1.17 \pm 0.02$ & $1.37 \pm 0.09$ & $=\mathbf{0 . 0 0 2 ^ { * * }}$ \\
\hline
\end{tabular}

*Chi-square analysis was used to compare the frequency among groups

**Independent t-test was used to compare the means among groups

$D M$ diabetes mellitus, $A F$ atrial fibrillation, $P S D$ post stroke dementia

The prevalence of our PSD was significantly higher in unmarried, non-working, old aged, and illiterate subjects, likewise other studies that proved non marriage [23, 24], unemployment [25], advanced age [26, 27], and low education [28-33] were the major determinants of PSD. The cognitive reserve hypothesis postulated that a higher level of education is a protective against dementia, where it increases neuronal plasticity and connectivity [34].

Also, likewise other studies [28, 35, 36], we reported that the prevalence of PSD was more frequent in rural than urban inhabitants, but the difference was insignificant $(P=0.234)$. This could be explained by the protective role of education, where in our country urban inhabitants have higher concern with education more than rural.

Although, most studies [37-39] concluded that the risk of PSD did not depend on gender and likewise other studies [40-42], our results detected PSD among female more than male patients but the difference was insignificant $(P=0.344)$. This high prevalence may be explained by hormonal changes, lifestyles, and low level of education among females, and it supported the hypothesis that gender has an important role in development and organization of brain function [43].

Table 3 Clinical manifestations among the studied stroke cases

\begin{tabular}{|c|c|c|c|}
\hline Variable & Without PSD $(n=301)$ & With PSD $(n=79)$ & $P$ value* \\
\hline \multicolumn{4}{|l|}{ Motor deficit } \\
\hline • Hemiplegia & $54(17.9 \%)$ & $27(34.2 \%)$ & $=0.002^{*}$ \\
\hline - Hemiparesis & $247(82.1 \%)$ & $52(65.8 \%)$ & \\
\hline Affected sphincter & $57(18.9 \%)$ & $49(62 \%)$ & $<0.001^{*}$ \\
\hline Gait affection & 85 (28.2\%) & $35(44.3 \%)$ & $=0.006^{*}$ \\
\hline Dysarthric speech & 79 (26.2\%) & $30(38 \%)$ & $=0.009^{*}$ \\
\hline Psychotic features & $6(2 \%)$ & $21(26.6 \%)$ & $<0.001^{*}$ \\
\hline Early seizures & $33(11 \%)$ & $14(17.7 \%)$ & $=0.104^{*}$ \\
\hline Extrapyramidal signs & $13(4.3 \%)$ & $10(12.7 \%)$ & $=0.010^{*}$ \\
\hline \multicolumn{4}{|l|}{ Stroke subtype } \\
\hline - Ischemic/Haemorrhagic & $254 / 47$ & $73 / 6$ & $=0.044^{*}$ \\
\hline - Cardio-embolic Stroke & 17 (5.6\%) & $16(20.3 \%)$ & $<0.001^{*}$ \\
\hline \multicolumn{4}{|l|}{$\mathrm{CT} /$ or MRI findings } \\
\hline - Brain atrophy & $42(14 \%)$ & $46(58.2 \%)$ & $<0.001^{*}$ \\
\hline - Bilateral lesions & $21(7 \%)$ & $17(21.5 \%)$ & $<0.001^{*}$ \\
\hline - Small vessel disease & $5(1.7 \%)$ & $9(11.4 \%)$ & $<0.001^{*}$ \\
\hline $\mathrm{Bl}$ & $80.91 \pm 12.5$ & $67.72 \pm 9.1$ & $=0.001^{* *}$ \\
\hline BI (PoorNery Poor) & $133(44.2 \%)$ & $61(77.2 \%)$ & $<0.001^{*}$ \\
\hline
\end{tabular}

${ }^{*}$ Chi-square analysis was used to compare the frequency among groups

"Independent t-test was used to compare the means among groups

CT computed tomography, BI Barthel Index, PSD post stroke dementia 


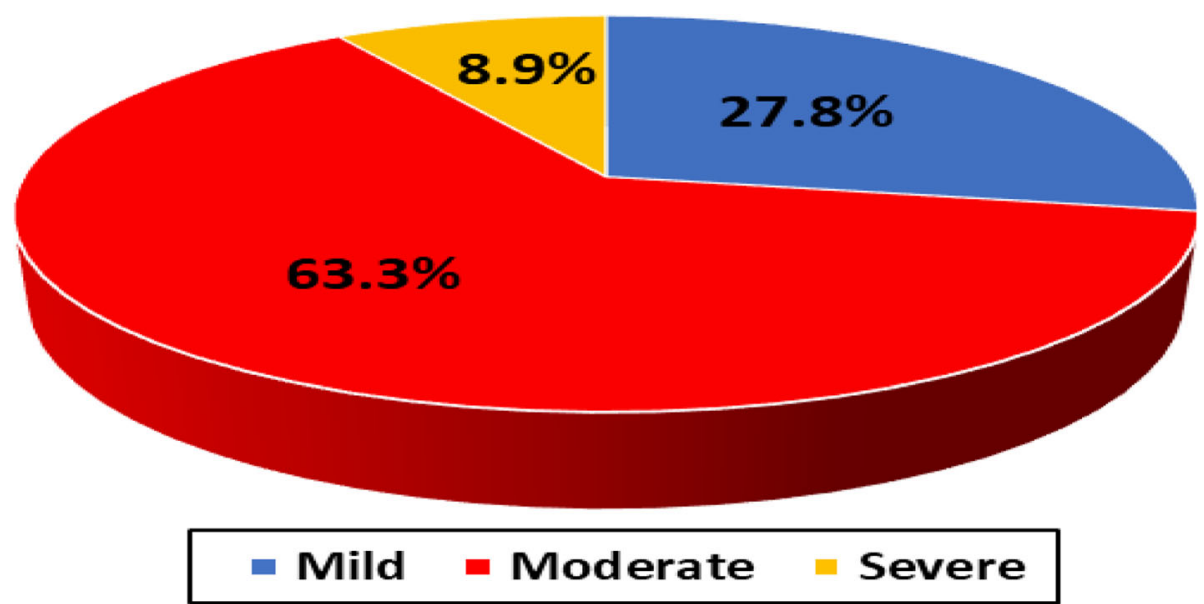

Fig. 2 PSD categories according to MMSE

The present study demonstrated that AF is an important predictor of cognitive outcome after stroke. A cohort study on AF diagnosed after stroke, published by Michal and colleagues, 2019 [44] showed that AF diagnosed after stroke increased the incident dementia, and patients on anticoagulant have a lower risk to develop dementia. The high incidence of PSD in patients with AF may be explained by the high frequency of subclinical micro infarcts and recurrent stroke, in addition to the severity of stroke in patients with AF. Furthermore, patients with AF may have atrial cardiomyopathy, endothelial dysfunction and fibrosis, and atrial hypercoagulability, which may act as a source of embolization [45].

The results of our study like previous studies [4648] had shown that diabetes mellitus was associated with an increased risk of PSD; this may be attributed to the high prevalence of atherosclerosis and arteriosclerosis in diabetics, impaired cerebral autoregulation, and increased blood viscosity. On the other hand, the other vascular risk profiles, other than

Table 4 Predictors of dementia among stroke patients: logistic regression model

\begin{tabular}{|c|c|c|c|c|}
\hline \multirow[t]{2}{*}{ Variable } & \multicolumn{2}{|l|}{ Univariate } & \multicolumn{2}{|l|}{ Multivariate } \\
\hline & OR $(95 \% \mathrm{Cl})$ & $P$ value & OR $(95 \% \mathrm{Cl})$ & $P$ value \\
\hline Age/years & $1.087(1.059-1.115)$ & $<0.001$ & $1.024(0.985-1.065)$ & $=0.233$ \\
\hline Sex & $1.143(0.695-1.890)$ & $=0.589$ & $1.098(0.587-3.656)$ & $=0.425$ \\
\hline Work status (unemployed) & $3.154(1.51-6.224)$ & $=0.003$ & & \\
\hline Illiterate & $4.043(2.300-7.106)$ & $<0.001$ & 1.597 (1.019-5.156) & $=0.041$ \\
\hline Unmarried & $2.440(1.436-4.146)$ & $=0.001$ & & \\
\hline $\mathrm{AF}$ & $10.042(4.149-24.305)$ & $<0.001$ & $6.112(2.002-11.192)$ & $=0.005$ \\
\hline Ischemic stroke & $2.011(1.043-3.957)$ & $=0.073$ & & \\
\hline Cardio-embolic stroke & $4.243(2.034-8.850)$ & $<0.001$ & & \\
\hline Number of stroke & $1.752(1.197-2.564)$ & $=0.004$ & & \\
\hline CT (brain atrophy) & $8.596(4.943-14.949)$ & $<0.001$ & $4.751(2.278-7.910)$ & $<0.001$ \\
\hline CT (bilateral lesions) & 3.656 (1.823-7.334) & $<0.001$ & & \\
\hline CT (small vessel disease) & $7.611(2.474-23.417)$ & $<0.001$ & & \\
\hline Bl (poor/very poor) & $4.281(2.414-7.591)$ & $<0.001$ & $3.924(1.289-5.114)$ & $=0.002$ \\
\hline Motor deficit (hemiplegic) & $2.375(1.370-4.118)$ & $=0.002$ & $3.123(1.152-5.025)$ & $=0.012$ \\
\hline Sphincteric affection & $6.992(4.082-11.967)$ & $<0.001$ & $2.332(1.101-4.937)$ & $=0.027$ \\
\hline Gait affection & $2.021(1.214-3.366)$ & $=0.007$ & $1.724(1.014-4.687)$ & $=0.049$ \\
\hline Psychotic Features & $17.802(6.885-46.028)$ & $<0.001$ & $9.231(3.158-21.348)$ & $=0.001$ \\
\hline PS Extrapyramidal Manifestations & $3.211(1.352-7.627)$ & $=0.008$ & & \\
\hline
\end{tabular}




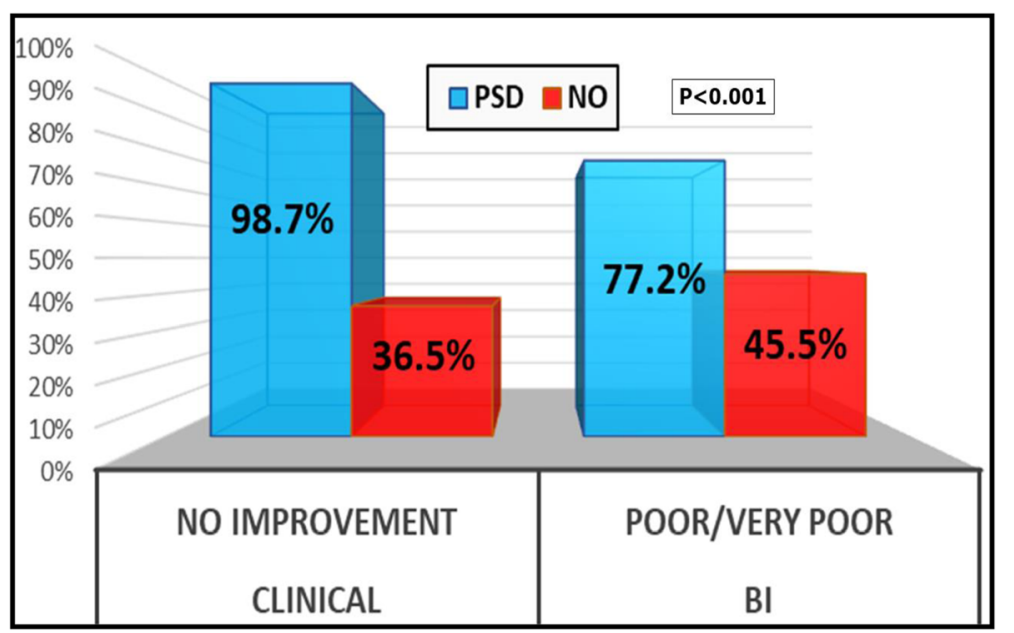

Fig. 3 Outcome comparisons among the studied stroke cases

diabetes, indirectly affect PSD through cerebral infarcts and white matter changes.

In the current study, recurrent or severe stroke, multiinfarcts or small vessel disease in neuroimaging, and sphincter disturbance were associated with increased risks of PSD. This may be attributed to intracerebral circuit interruption or functional cortical disconnection, in addition to the effect of inflammatory mediators of the vascular insult or the systemic complications. A recent study by Pendlebury and Rothwell [48] mentioned that long-term risk of dementia can be reduced by appropriate stroke car.

Although, previous studies [38-40] stated that the risk of PSD and its severity were not influenced by the type of stroke (ischemic or haemorrhagic), our study demonstrated PSD more significantly among ischemic than hemorrhagic stroke patients $(P=0.044)$. This could be explained by the fact that cerebral infarction causes more wide spread massive damage to brain parenchyma and its occurrence in relatively old age with impaired vascular supply increases the probability of dementia.

Our results showed that stroke survivors who presented by focal neurological manifestations such as hemiplegia, dysarthria, affected sphincters, gait disorder, extrapyramidal signs, or psychotic manifestations had a significantly higher risk of PSD. This may be attributed to the site of the lesion, and decreased physical activity.

In the current study, PSD was found to be associated with psychotic symptoms. The relationship between psychotic manifestations and PSD is still undefined, as the relation may be bidirectional, or they may occur independently. Robertson and colleagues [49] stated that both psychotic symptoms and cognitive deficits were related to the site of the lesion, as they noticed that patient with psychotic manifestations had left sided lesion, but in the current study, we cannot confirmed that as we excluded patients with severe aphasia. Furthermore, another study demonstrated that psychotic symptoms were prevalent in patients with severe cognitive deficit [50].

More than $90 \%$ of our patients had mild and moderate degrees of PSD which were comparable to those of El Tallawy and his colleagues in their studies in Al Kharga and Al-Quseir cities $[28,29]$. So that, the majority of our PSD patients were candidates for treatment, this encourages us for further studies on PSD treatment protocols.

Our results confirmed the postulation of other studies [9-11], which stated that PSD can contribute to worse outcome through lack of compliance and less intensive stroke management, where only about $1 \%$ of our patients with PSD showed clinical improvement. These patients were highly dependent in instrumental activities of daily living that required more complex tasks [51] and according to BI, more than three-quarters $(77.2 \%)$ of them had poor and very poor outcome as compared to less than half of patients without dementia (45.5\%).

The results of the present study should be interpreted in the light of the following limitations. First, lack of a uniform diagnostic criteria, specific assessment tools, and reliable markers such as a biochemical marker for identification of PSD. Second, inability to have serial assessments of cognitive function with inability to assess different cognitive domains.

Multi-centres' future researches should be given high priority on the pathophysiology and long-term cognitive outcomes of stroke patients; this may come up with new diagnostic neuroimaging techniques and biomarkers for early recognition of PSD.

\section{Conclusion}

This research indicated that PSD is a quite common problem and may adversely affect outcome of stroke. So, assessment of cognitive status at an early stage of stroke 
and identifying post-stroke risk factors and predictors of cognitive impairment are very important. This will assist in the prevention of further cognitive decline and improve psychological wellbeing through effective intervention.

\section{Abbreviations}

PSD: Post-stroke dementia; AF: Atrial fibrillation; BI: Barthle Index; CVS: Cerebrovascular stroke; ECG: Electrocardiography

\section{Acknowledgements}

We acknowledge the help and support of the medical and administrative staff of the neuropsychiatric department, Aswan and Assuit University Hospitals. It was not possible to complete this work without the help, support, and approval of the patients' caregiver.

\section{Authors' contributions}

BA: concept, design, literature search, clinical studies, manuscript preparation, editing, and review. MA: definition of intellectual content, literature search, and manuscript review. Al: methodological design, data analysis, statistical analysis, manuscript preparation, editing, and review. All authors have read and approved the manuscript.

\section{Funding}

No funding received in this study.

\section{Availability of data and materials}

Data and materials supporting the results of this article are available with the authors on reasonable request.

\section{Ethics approval and consent to participate}

Approval for this study was obtained from IRB of Medical Faculty, Aswan University prior to study execution (IRB No. Asw-376-7-19). The research complied with Helsinki. In addition, all subjects (or their parents or legal guardians) have given their written informed consent. The written informed consent was clear and indicated the purpose of the study, and their freedom to participate or withdraw at any time without any obligation. Furthermore, participants' confidentiality and anonymity were assured by assigning each participant with a code number for the purpose of analysis only. The study was not based on any incentives or rewards for the participants.

\section{Consent for publication}

Not applicable in this section.

\section{Competing interests}

The authors have no conflicts of interest to declare.

\section{Author details}

${ }^{1}$ Neurology and Psychiatry Department, Aswan University, Aswan, Egypt.

${ }^{2}$ Community Medicine Department, Assiut University, Assiut, Egypt.

${ }^{3}$ Neurology and Psychiatry Department, and Neuroepidemiology Laboratory, Faculty of Medicine, Assiut University, Assiut University street, Neuropsychiatric Hospital, 7th floor, Assiut 71926, Egypt.

\section{Received: 19 October 2020 Accepted: 12 January 2021}

\section{Published online: 01 February 2021}

\section{References}

1. Delbari A, Roghani RS, Tabatabaei SS, Rahgoza M, Lokk J. Stroke epidemiology and one-month fatality among an urban population in Iran. Int J Stroke. 2011;6(3):195-200.

2. Ankolekar S, Geeganage C, Anderton P, Hogg C, Bath PM. Clinical trials for preventing post stroke cognitive impairment. J Neurol Sci. 2010;299(12): 168-74.

3. Stephens S, Kenny RA, Rowan E, Allan L, Kalaria RN, Bradbury M, et al. Neuropsychological characteristics of mild vascular cognitive impairment and dementia after stroke. Int J Geriatr Psychiatry. 2004;19(11):1053-7.

4. Erkinjuntti T. Diagnosis and management of vascular cognitive impairment and dementia. J Neural Transm Suppl. 2002;63:91-109.
5. Leys D, Hénon H, Cordoliani M, Pasquier F. Post stroke dementia. Lancet Neurol. 2005:4(11):752-9.

6. Gorelick PB, Nyenhuis D. Stroke and cognitive decline. JAMA. 2015;314(1): 29-30.

7. Chi Hu G, Chen Y. Post-stroke dementia: epidemiology, mechanisms and management. Int J Gerontol. 2017:1-5.

8. Moroney JT, Bagiella E, Tatemichi TK, Paik MC, Stern Y, Desmond DW. Dementia after stroke increases the risk of long-term stroke recurrence. Neurology. 1997:48:1317-25.

9. Iadecola C. The pathology of vascular dementia. Neuron. 2013;80:844-66.

10. Barba R, Morin MD, Cemillán C, Delgado C, Domingo J, Del Ser T. Previous and incident dementia as risk factors for mortality in stroke patients. Stroke. 2002:33(8):193-8.

11. Hénon H, Durieu I, Lebert F, Pasquier F, Leys D. Influence of pre-stroke dementia on early and delayed mortality in stroke patients. J Neurol. 2003; 250(1):10-6

12. Melkas S, Oksala NK, Jokinen H, Pohjasvaara T, Vataja R, Oksala A, et al. Post stroke dementia predicts poor survival in long-term follow-up: influence of pre-stroke cognitive decline and previous stroke. J Neurol Neurosurg Psychiatry. 2009;80(8):865-70.

13. Xiu S, Zheng Z, Liao Q, Chan P. Different risk factors for cognitive impairment among community- dwelling elderly with impaired fasting glucose or diabetes. Diabetes Metab Syndr Obes. 2019;12:121-30.

14. Mahoney Fl, Barthel D. Functional evaluation: the Barthel Index. Md Med J. 1965;14:61-5.

15. Hachinski VC, Iliff LD, Zilhka E, Du Boulay GH, McAllister VL, Marshall J, et al. Cerebral blood flow in dementia. Arch Neurol. 1975;32:632-7.

16. American Psychiatric Association [APA]. Diagnostic and statistical manual of mental disorders. 5th ed. Washington, DC: American Psychiatric Association; 2013.

17. Folstein M, Folstein S, Mc HP. Mini-Mental State: a practical guide for grading the cognitive state of patients for the clinician. J Psychiatr Res. 1975:53:189-98

18. Faul F, Erdfelder E. George lang A. Buchner A. G*Power 3: A flexible statistical power analysis program for the social, behavioral, and biomedical sciences. Behav Res Methods. 2007;39(1):175-91.

19. IBM_SPSS, Statistical Package for Social Science. Ver.21. Standard version, S Inc, Editor 2012, Copyright @ SPSS Inc: NY-USA

20. Hénon H, Pasquier F, Leys D. Post-stroke dementia. Cerebrovasc Dis. 2006; 22:61-70

21. Cristina SI, Sudha S, Alexa B, Rhoda A, Carlos SK, Margaret KH, et al. Dementia after stroke: The Framingham Study. Stroke. 2004;35:1264-8.

22. Iranmanesh F, Sheykholeslami NZ, Rahimdel A, Gadari F, Vazirinajad R, SyedYazdi F. Post-stroke dementia and its putative risk factors: a hospitalbased study. Pakistan J Neurol Sci (PJNS). 2015;10(1):192-8.

23. Lindén T, Skoog I, Fagerberg B, Steen B, Blomstrand C. Cognitive impairment and dementia 20 months after stroke. Neuroepidemiology. 2004:23(12):45-52

24. Tu Q, Ding B, Yang X, Bai S, Tu J, Liu Z, et al. The current situation on vascular cognitive impairment after ischemic stroke in Changsha. Arch Gerontol Geriatr. 2014;58(2):236-47

25. Mahon S, Parmar P, Barker-Callo S, Krishnamurthi R, Jones K, Theadom R, et al. Determinants, prevalance, and trajectory of long-term post-stroke cognitive impairment: results from a 4-year follow-up of the ARCOS-IV study. Neuroepidemiology. 2017;49:129-34.

26. Borenstein AR, Copenhaver $\mathrm{Cl}$, Mortimer JA. Early life risk factors for Alzheimer disease. Alzheimer Dis Assoc Disord. 2006;20:63-72.

27. Zhou DH, Wang JY, Li J, Deng J, Gao C, Chen M. Study on frequency and predictors of dementia after ischemic stroke: Chongqing stroke study. J Neurol. 2004;251:421-7.

28. El Tallawy HN, Farghly WM, Shehata GA, Hakeem NA, Rageh T, Abo-Elfetoh $\mathrm{N}$, et al. Prevalence of dementia in Al Kharga District, New Valley Govern., Egypt. Neuroepidemiology. 2012;38(3):130-7.

29. El Tallawy HN, Farghly WM, Rageh TA, Badry R, Abdelhakim N, Abd elhameed $\mathrm{M}$, et al. Prevalence of dementia in Al-Quseir city, Red Sea Governorate, Egypt. Clin Interv Aging. 2014;(9):9-14.

30. Khedr E, Fawi G, Abbas MA, Mohammed T, Aboelfotoh N, Noaman M, et al. Prevalence of mild cognitive impairment and dementia among the elderly population of Qena Governorate, Upper Egypt: a community-based study. J Alzheimers Dis. 2015:45(1):117-26.

31. Perneczky R, Wagenpfeil S, Lunnetta KL, Cupples LA, Green RC, Decarli C, et al. Education attenuates the effect of medial temporal lobe atrophy on 
cognitive function in Alzheimer's disease: The MIRAGE study. J Alzheimers Dis. 2009;17:855-62.

32. Sharp ES, Gatz M. Relationship between education and dementia: an updated systematic review. Alzheimer Dis Assoc Disord. 2011;25(4):289-304.

33. Brayne C, Ince PG, Keage HA, McKeith IG, Matthews FE, Polvikoski T, et al. Education, the brain and dementia: Neuroprotection or compensation? Brain. 2010;13(3):2210-6.

34. Mirza SS, Portegies ML, Wolters FJ, Hofman A, Koudstaal PJ, Tiemeier H, et al. Higher education is associated with a lower risk of dementia after a stroke or TIA. The Rotterdam Study. Neuroepidemiology. 2016;46:120-7.

35. Farrag A, Farwiz HM, Khedr EH, Mahfouz RM, Omran SM. Prevalence of Alzheimer's disease and other dementing disorders: Assiut-Upper Egypt study. Dement Geriatr Cogn Disord. 1998;9(6):323-8.

36. Rorsman B, Hagnell O, Lanke J. Prevalence and incidence of senile and multi-infarct dementia in the Lundby Study: a comparison between the time periods 1947-1957 and 1957-1972. Neuropsychobiology. 1986;15(3-4): $122-9$.

37. Tang WK, Chan SS, Chiu HF, Ungvari GS, Wong KS, Kowk T, et al. Frequency and determinants of post-stroke dementia in Chinese. Stroke. 2004;35:930-5.

38. Henon H, Durieu I, Guerouaou D, Lebert F, Pasquier F, Leys D. Post-stroke dementia: incidence and relationship to pre-stroke cognitive decline. Neurology. 2001;57:1216-22.

39. Altieri M, Di Piero V, Pasquini M. Delayed post-stroke dementia: a 4-year follow-up study. Neurology. 2004;62:2193-7.

40. Nitrini R, Bottino CM, Albala C, Capunay SC, Ketzoian C, Rodriquez JJ, et al. Prevalence of dementia in Latin America: a collaborative study of population-based cohorts. Int Psychogeriatr. 2009;21(4):622-30.

41. Bennett DA, Wilson RS, Schneider JA, Evans DA, Beckett LA, Aggarwal NT, et al. Natural history of mild cognitive impairment in older persons. Neurology. 2002;59:198-205.

42. Guerchet M, M'belesso P, Mouanga AM, Bandzouzi B, Tabo A, Houinato DS, et al. Prevalence of dementia in elderly living in two cities of Central Africa: the EDAC survey. Dement Geriatr Cogn Disord. 2010;30:261-8.

43. Gabelli C, Codemo A. Gender differences in cognitive decline and Alzheimer's disease. Ital J Gender-Specific Med. 2015;1:21-8.

44. Michal K, Sebastian F, Cheng Y, Jiming F, Gustavo S. Atrial fibrillation diagnosed after stroke and dementia risk: cohort study of first-ever ischemic stroke patients aged 65 or older. Europace. 2019;(0):1-9.

45. Heijman J, Voigt N, Nattel S, Dobrev D. Cellular and molecular electrophysiology of atrial fibrillation initiation, maintenance, and progression. Circ Res. 2014;114:1483.

46. Yang J, Wong A, Wang Z, Liu W, Au L, Xiong Y, et al. Factors for incident dementia after stroke and transient ischemic attack. Alzheimer Dement. 2015:11:16-23

47. Béjot $Y$, Aboa-Eboulé C, Durier J, Rouaud $\mathrm{O}$, Jacquin $\mathrm{A}$, Ponavoy E, et al. Prevalence of early dementia after first ever stroke: a 24-year populationbased Study. Stroke. 2011;42:607-12.

48. Pendlebury ST, Rothwell PM. Prevalence, incidence, and factors associated with pre-stroke and post-stroke dementia: a systematic review and metaanalysis. Lancet Neurol. 2009:8(11):1006-18.

49. Turner-Stokes L. Post stroke depression: getting the full picture. Lancet. 2003:361:1757-8.

50. Rasquin S, Lodder J, Verhey F. The association between psychiatric and cognitive symptoms afer stroke: a prospective study. Cerebrovasc Dis. 2005; 19(5):309-16.

51. Claesson L, Linden T, Skoog I, Blomstrand C. Cognitive impairment after stroke impact on activities of daily living and costs of care for elderly people: the Goteborg 70+ stroke study. Cerebrovasc Dis. 2005;19(2):102-9.

\section{Publisher's Note}

Springer Nature remains neutral with regard to jurisdictional claims in published maps and institutional affiliations.

\section{Submit your manuscript to a SpringerOpen ${ }^{\circ}$ journal and benefit from:}

- Convenient online submission

- Rigorous peer review

- Open access: articles freely available online

- High visibility within the field

- Retaining the copyright to your article

Submit your next manuscript at $\boldsymbol{\nabla}$ springeropen.com 